Research Paper

\title{
Loss of $\beta$-arrestin-2 and Activation of CXCR2 Correlate with Lymph Node Metastasis in Non-small Cell Lung Cancer
}

\author{
Lei Cong ${ }^{1 *}$, Zhi-yong Qiu ${ }^{*}$, Yang Zhao ${ }^{2,3}$, Wei-bo Wang ${ }^{1}$, Cai-xia Wang ${ }^{1}$, Hong-chang Shen ${ }^{1 凶}$, Jun-qing \\ $\mathrm{Han}^{1 凶}$ \\ 1. Department of Oncology, Shandong Provincial Hospital Affiliated to Shandong University, \#324 Jingwu Road, Jinan 250021, P.R.China; \\ 2. Department of Breast Surgery, Key Laboratory of Breast Cancer in Shanghai, Collaborative Innovation Center of Cancer Medicine, Fudan University \\ Shanghai Cancer Center, Shanghai, 200030, China; \\ 3. Department of Oncology, Shanghai Medicine College, Fudan University, Shanghai, 200030, China. \\ * Lei Cong and Zhi-yong Qiu contributed equally to this work. \\ $\square$ Corresponding authors: Jun-qing Han and Hong-chang Shen, Department of Oncology, Provincial Hospital Affiliated to Shandong University, Shandong \\ University, \#324 Jingwu Road, Jinan 250021, P.R.China. Tel: +86-531-68777923; Fax: +86-531-68777100; Email: hanjunqing1960@126.com; shc11312@hotmail.com. \\ (C) Ivyspring International Publisher. This is an open access article distributed under the terms of the Creative Commons Attribution (CC BY-NC) license \\ (https://creativecommons.org/licenses/by-nc/4.0/). See http://ivyspring.com/terms for full terms and conditions.
}

Received: 2017.02.13; Accepted: 2017.06.01; Published: 2017.08.23

\begin{abstract}
Background: Although $\beta$-arrestin-2 ( $\beta$-arr2) and CXCR2 have been shown to affect various malignant tumors, their exact roles in lung cancer remain unclear. We investigated expression of $\beta$-arr2 and CXCR2 in patients with non-small cell lung cancer (NSCLC) and their correlation with lymph node metastasis and prognosis.

Methods: We reviewed medical records of 136 patients with NSCLC who underwent surgical resection, and assessed their specimens immunohistochemically for expression of $\beta$-arr 2 and CXCR2 in primary tumors and metastatic lymph nodes (MLNs), respectively.

Results: High $\beta$-arr2 expression was seen in 63 specimens (46.3\%), and was significantly associated with male patients $(P=0.011)$, squamous cell carcinoma $(P=0.003)$, and lymph node metastasis $(P<0.001)$. High CXCR2 expression was seen in 62 specimens $(45.6 \%)$, and was significantly correlated only with lymph node metastasis $(P<0.001)$. Expression of $\beta$-arr 2 was significantly lower at $M L N s$ than at primary lesions $(Z=-2.315 ; P=0.021$; Wilcoxon signed-rank), whereas $C X C R 2$ expression was significantly higher in MLNs than in primary lesions $(Z=-3.712$; $P<0.001$; Wilcoxon signed-rank). No relationship was seen between $\beta$-arr2 and CXCR2 expression in primary lesions $(r=-0.065, P=0.548$; Spearman rank coefficient), but they were inversely related in MLNs $(r=-0.263, P=0.012)$. Kaplan-Meier survival curve was shown that low $\beta$-arr2 and high CXCR2 expressions was associated with poor survival (log-rank: $\left.X^{2}=5.926, P=0.015\right)$.

Conclusions: $\beta$-arr 2 may promote lymph node metastasis in NSCLC by modulating CXCR2 activation.
\end{abstract}

Key words: non-small cell lung cancer; $\beta$-arrestin-2; CXCR2; immunohistochemistry.

\section{Introduction}

Expression of the $\mathrm{ELR}^{+}$(glutamic acid-leucine-arginine) chemokines, CXCL1-3 and CXCL5-8, in lung cancer cells has been associated with malignant transformation, cell migration, angiogenesis, tumorigenesis, and metastasis of lung cancer in vitro and in vivo [1, 2]. The ELR ${ }^{+}$chemokines induce down-stream cellular signals mediated via CXC chemokine receptor 2 (CXCR2) [3, 4], which is a G-protein-coupled receptor (GPCR). As with other GPCRs, CXCR2 is modulated by desensitization and 
internalization via several adaptor/scaffold proteins, including $\beta$-arrestins $[5,6,7]$.

Arrestins were identified as mediators of GPCR desensitization and endocytosis, and bind to most GPCRs after agonist activation and phosphorylation of receptors by GPCR kinases. There are four members of the arrestin family: Visual arrestin (arrestin 1) is found in retinal rods and cones, whereas $X$-arrestin (arrestin 4) is located exclusively at retinal cones; $\beta$-arrestin 1 and 2 (arrestins 2 and 3, respectively) are ubiquitously distributed. $\beta$-arrestin-1 and -2 ( $\beta$-arr2), which share a high conserved sequence similarity, bind to the CXC chemokine receptors CXCR1 and CXCR2 and regulate cellular responses to these receptors $[6,8]$. Reportedly, $\beta$-arr2-deficient $(\beta$-arr2-/-) mice have delayed CXCR2 internalization but enhanced cellular responses, including $G$ protein activation and respiratory burst [9]. Further, $\beta$-arr2-/- mice exhibited significantly increased Lewis lung cancer tumor growth and metastasis relative to $\beta$-arr $2^{+/+}$mice; $\beta$-arr 2 modulates tumorigenesis by regulating inflammation and angiogenesis through activation of CXCR2 [2]. However, the pathological significance of $\beta$-arr2 and CXCR2 in lung cancer remains unclear. Therefore, we examined expression of $\beta$-arr2 and CXCR2 in primary tumors and metastatic lymph nodes (MLNs) respectively from patients with non-small cell lung cancer (NSCLC), and association between these expressions and clinicopathological characteristics.

\section{Materials and Methods}

\section{Cells and cell culture}

Human lung adenocarcinoma cell lines A549, SPC, and H1975 were obtained from American Type Culture Collection (Manassas, VA). The A549 and H1975 cell lines were grown in RPMI medium supplemented with $10 \%$ fetal bovine serum (FBS) and $1 \%$ penicillin-streptomycin (PS). SPC cells was cultured in DMEM supplemented with 10\% FBS and $1 \%$ PS. All cells were maintained in a humidified atmosphere of $5 \% \mathrm{CO}_{2}$ at $37^{\circ} \mathrm{C}$.

\section{Patients}

We enrolled 136 patients with pathological confirmed, newly diagnosed NSCLC who underwent surgery between January 2006 and June 2008 at the Provincial Hospital affiliated to Shandong University. The eligibility criteria were: (a) Karnofsky performance score $\geq 70$; (b) age 18 - 75 years; (c) adenocarcinoma (ADC) or squamous cell carcinoma (SCC); (d) underwent adjuvant therapy after surgery without distant metastasis; (e) survived for $>3$ months after surgery; and (f) followed up at least 4 years after surgery. Patients were excluded if they (a) were previously diagnosed with another cancer; (b) were diagnosed simultaneously with multiple tumors; (c) received preoperative treatment; or (d) died of any cause other than lung cancer. This study was performed in accordance with the ethical standards formulated in the Helsinki Declaration of 1964 and approved by the Shandong Provincial Hospital's Ethics Committee.

\section{Tissue samples}

Resected specimens were partly fixed in $4 \%$ formalin and embedded in paraffin for immunohistochemistry (IHC), and partly frozen at $-80^{\circ} \mathrm{C}$ for proteins assay. Multiple IHC-stained sections of NSCLC tumors and their related lymph nodes were examined for $\beta$-arr2 and CXCR2. Tumor differentiation and stage were determined according to the WHO and UICC criteria, respectively. Patients' clinicopathological characteristics are summarized in Table 1.

Table 1. Relations of clinical and pathological characteristics and $\beta$-arrestin-2/CXCR2 in NSCLC patients

\begin{tabular}{|c|c|c|c|c|c|c|c|c|}
\hline \multicolumn{5}{|c|}{ Characteristics $\beta$-arrestin-2 } & \multicolumn{4}{|c|}{ CXCR2 } \\
\hline & \multicolumn{2}{|c|}{$\begin{array}{l}\text { No. of } \\
\text { patients }\end{array}$} & \multirow[t]{2}{*}{$x^{2}$} & \multirow[t]{2}{*}{$P$ value } & \multicolumn{2}{|c|}{$\begin{array}{l}\text { No. of } \\
\text { patients }\end{array}$} & \multirow[t]{2}{*}{$x^{2}$} & \multirow[t]{2}{*}{$P$ value } \\
\hline & Low & High & & & Low & High & & \\
\hline \multicolumn{9}{|l|}{ Sex } \\
\hline Male & 46 & 52 & 6.404 & 0.011 & 54 & 44 & 0.067 & 0.795 \\
\hline Female & 27 & 11 & & & 20 & 18 & & \\
\hline \multicolumn{9}{|l|}{ Age $^{*}$} \\
\hline$>60$ & 34 & 30 & 0.015 & 0.903 & 33 & 31 & 0.396 & 0.529 \\
\hline$\geq 60$ & 39 & 33 & & & 41 & 31 & & \\
\hline \multicolumn{9}{|l|}{$\begin{array}{l}\text { Smoking } \\
\text { Index }\end{array}$} \\
\hline Never & 14 & 23 & 5.603 & 0.061 & 16 & 21 & 5.541 & 0.063 \\
\hline$<400$ & 17 & 9 & & & 19 & 7 & & \\
\hline$\geq 400$ & 42 & 31 & & & 39 & 34 & & \\
\hline \multicolumn{9}{|c|}{ Tumor differentiation } \\
\hline Well & 15 & 16 & 5.644 & 0.059 & 13 & 18 & 2.562 & 0.278 \\
\hline Moderately & 32 & 36 & & & 39 & 29 & & \\
\hline Poorly & 26 & 11 & & & 22 & 15 & & \\
\hline \multicolumn{9}{|l|}{ Histology } \\
\hline Adenomas & 49 & 26 & 9.138 & 0.003 & 39 & 36 & 0.392 & 0.531 \\
\hline Squamous & 24 & 37 & & & 35 & 26 & & \\
\hline \multicolumn{9}{|l|}{ T stage } \\
\hline $\mathrm{T} 1$ & 33 & 22 & 1.485 & 0.223 & 28 & 27 & 0.457 & 0.499 \\
\hline $\mathrm{T} 2-4$ & 40 & 41 & & & 46 & 35 & & \\
\hline \multicolumn{9}{|l|}{ LN metastasis } \\
\hline Negative & 37 & 12 & 14.685 & $<0.001$ & 12 & 37 & 27.647 & $<0.001$ \\
\hline Positive & 36 & 51 & & & 62 & 25 & & \\
\hline
\end{tabular}

Abbreviations: LN: lymph node.

*Age ranges from 18 to 75 years according to the inclusion criteria.

\section{Immunohistochemistry}

All tissue blocks were sectioned (thickness: 4 $\mu \mathrm{m})$. We made 6 sections for every individual, 2 of which were stained with hematoxylin-eosin for histopathological analysis by two pathologists; the 
others were used for immunostaining. Sections were deparaffinized and rehydrated as normal; 3\% $\mathrm{H}_{2} \mathrm{O}_{2}$ was then used to block endogenous peroxidase activity. After that, antigens were retrieved by microwave, and non-specific antigens were blocked with goat serum. Sections were then incubated overnight at $4^{\circ} \mathrm{C}$ with primary antibodies diluted in PBS with $0.05 \%$ Tween-20: 1:500 for anti- $\beta$-arr2 antibody (Cell Signaling Technology, Danvers, MA, USA), and 1:200 for anti-CXCR2 antibody (Abcam Ltd., HKSP, HK). HRP-conjugated conjugated secondary antibody was applied to detect immunoreactivity. Slides were counterstained with hematoxylin, washed, dehydrated in an ethanol gradient, and cover-slipped. The primary antibodies were substituted by PBS as negative controls.

\section{Immunohistological evaluation}

To evaluate $\beta$-arr2 and CXCR2 expressions, we counted 1,000 tumor cells in contiguous 400× microscopic fields. $\beta$-arr2 was predominately expressed in cytoplasm and nucleus; and CXCR2 was mostly expressed in membrane and cytoplasm. A staining index (SI) was calculated as a product of staining intensity (0-3) and area of positive tumor cell nuclei (0: none; 1: $<10 \%$; 2: $10-50 \%$; and 3: $>50 \%$ ) [10]. Degree of $\beta$-arr2 and CXCR2 expressions was designated as follows: $0-1$, low expression; $2-3$, high expression. The results were assessed by two independent pathologists (X. Lin and Y. Liu), who were blinded to the immunohistological and clinical status. There was $5 \%$ disagreement; for discrepancies, the slides were simultaneously reexamined by two pathologists under a multi-headed microscope until consensus was achieved.

\section{SDS-PAGE and western blotting}

Protein samples were dissolved in a sample buffer containing $1 \mathrm{mM} \beta$-mercaptoethanol, Samples were analyzed by SDS-PAGE with a 4\%-12\% separation gel. After SDS-PAGE, the proteins were transferred to nitrocellulose membranes (GE Healthcare) at $4^{\circ} \mathrm{C}$ for $1 \mathrm{~h}$ and then blocked for $1 \mathrm{~h}$ at room temperature in a solution of $5 \%(\mathrm{w} / \mathrm{v})$ skimmed milk powder and $0.02 \%(\mathrm{w} / \mathrm{v})$ Tween 20 in PBS (pH 7.5). Incubation with appropriate primary antibodies was performed overnight at $4^{\circ} \mathrm{C}$. This was followed by washing with PBST and incubation with a horseradish peroxidase-labeled secondary antibody (Pierce) for $1 \mathrm{~h}$ at room temperature. The detection was made with ECL (Pierce). The films were exposed at different time points, and then developed and fixed.

\section{Statistical analysis}

The relationships between $\beta$-arr2 and CXCR2 expressions and patients' clinicopathological characteristics were analyzed by $\chi^{2}$ tests or Fisher exact tests. Multivariate logistic regression analysis was applied to estimate correlations between $\beta$-arr2 expression and clinical characteristics. Wilcoxon signed-rank test was used to analyze associations between $\beta$-arr2 and CXCR2 expressions in paired primary tumors and MLNs. Spearman rank test was applied to analyze correlations between $\beta$-arr2 and CXCR2. Kaplan-Meier survival curves were used to assess the effects of $\beta$-arr2 and CXCR2 expressions on 4 -year overall survival (OS), and the log-rank test was used to evaluate differences in survival distributions. $P<0.05$ was considered significant. All the statistical analyses were completed by SPSS software (version 17.0).

\section{Results}

\section{Expressions of $\beta$-arr2 and CXCR2 in ADC and SCC}

To verify the consistency of IHC and western blot results for $\beta$-arr2 and CXCR2 expressions, namely, to confirm the reliability of immunohistochemistry results, we randomly selected 4 ADC and 4 SCC samples from the 136 cases, together with 3 NSCLC cell lines, for further IHC and western blot analyses, respectively.

We detected the expression of $\beta$-arr2 and CXCR2 in the 11 preliminary test samples (3 NSCLC cell lines and 4 SCC and 4 ADC surgical specimens) by western blot, at molecular weights of $50 \mathrm{kDa}$ and $41 \mathrm{kDa}$ respectively (Figure 1A). Among the 11 test samples expressions of $\beta$-arr2 and CXCR2 proteins varied; however, higher $\beta$-arr2 expression implied lower CXCR2 expression. We used the same antibodies for IHC staining for $\beta$-arr2 and CXCR2 in the SCC and 4 ADC surgical specimens (Figure 1B, C); variations in $\beta$-arr2 and CXCR2 expression were in accord with the results detected by western blot (Figure 1A). The IHC staining predominantly detected $\beta$-arr2 in cytoplasm, and partly in nucleus; whereas CXCR2 staining was predominantly in the cell membranes.

\section{Relationships between $\beta$-arr2/CXCR2 expression and patients' clinicopathological characteristics}

High $\beta$-arr2 expression was seen in 63 patients $(46.3 \%)$. High $\beta$-arr2 expression (per $\chi^{2}$ tests) was more prevalent in men than women $(P=0.011)$; in SCC than $\operatorname{ADC}(P=0.003)$; and in $\mathrm{pN}>0$ specimens than pN0 specimens $(P<0.001)$. High CXCR2 expression was seen in 62 patients $(45.6 \%)$. High CXCR2 expression was significantly more prevalent in $\mathrm{pN} 0$ tumors than in $\mathrm{pN}>0$ tumors $(P<0.001)$, but correlated 
with no other clinicopathologic factors (Table 1). In multivariate logistic regression, high $\beta$-arr2 expression was only correlated with $\operatorname{ADC}(P=0.048)$ and lymph node metastases $(P<0.001$; Table $2 a)$.

Table 2a. Multivariate Logistic Regression Analysis for the correlation between $\beta$-arrestin-2 expressions and clinical characteristics

\begin{tabular}{lll}
\hline Variable & Adjusted OR (95\% CI ) & $P$ value \\
\hline Sex & $1.234(0.361-4.211)$ & 0.737 \\
Male & & \\
Female & & \\
Histology & 0.048 \\
Adenomas & $0.435(0.188-0.979)$ & \\
Squamous & & \\
LN metastasis & & \\
$\begin{array}{l}\text { Negative } \\
\text { Positive }\end{array}$ & $4.692(2.104-10.461)$ & \\
\hline Abbreviations: OR: Odds Ratio; CI: confidence interval; LN: lymph node.
\end{tabular}

A.

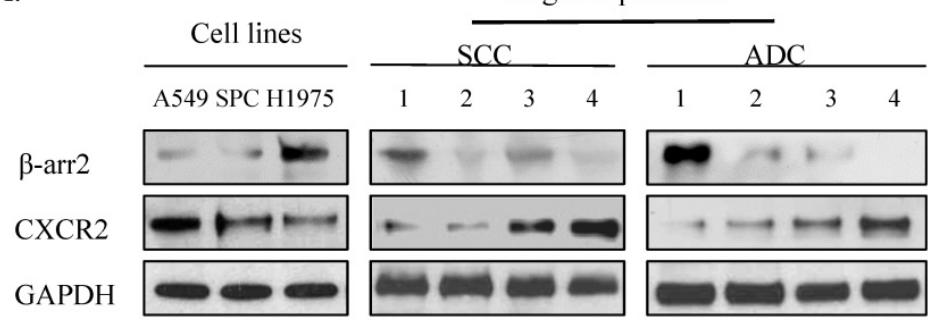

B. $\beta$-arr2

Strong

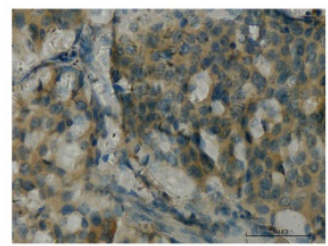

$\mathrm{ADC}$

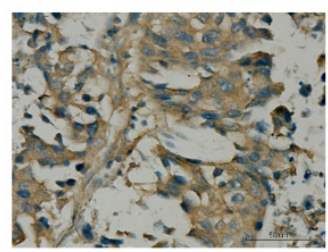

C.CXCR2

Strong

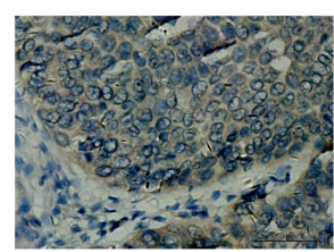

SCC

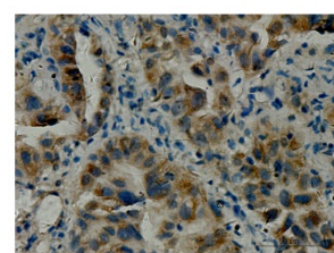

Weak
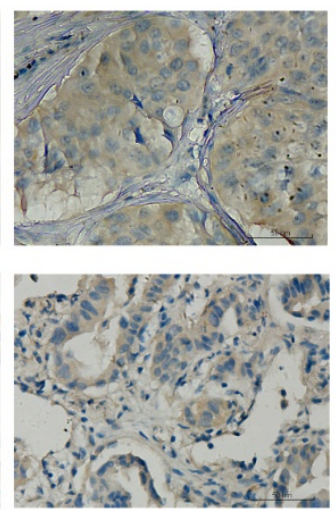

Negative
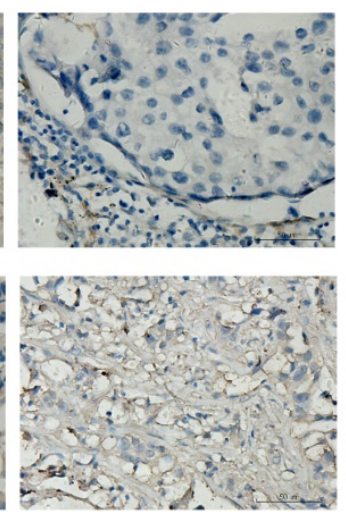

Weak
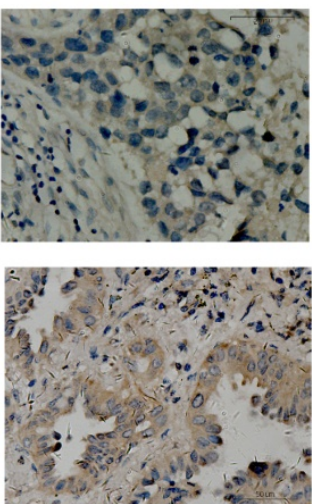
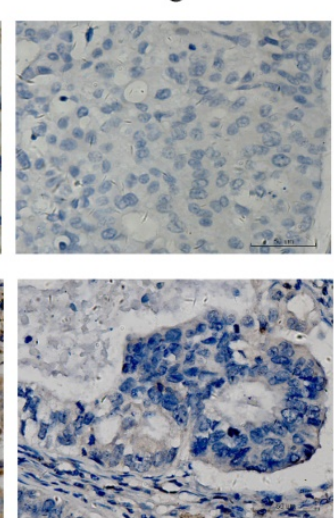

Figure 1. Expressions of $\beta$-arrestin-2 ( $\beta$-arr2) and CXCR2 in adenocarcinoma (ADC) and squamous cell carcinoma (SCC). A. Western blot showed $\beta$-arr2 (mw: 50 $\mathrm{kDa}$ ) and CXCR2 (mw: $41 \mathrm{kDa}$ ) expression in NSCLC cell lines and 8 surgical specimens (4 SCC and 4 ADC). B. Immunohistochemical staining is shown for $\beta$-arr2 in NSCLC (scale bar: $50 \mu \mathrm{m}$ ). C. Immunohistochemical staining is shown for CXCR2 in NSCLC (scale bar: $50 \mu \mathrm{m}$ ). 


\section{$\boldsymbol{\beta}$-arr2 and CXCR2 associated with MLNs}

Among the 136 patients, there were 87 cases who had paired surgical specimens of primary and MLN lesions. IHC testing for $\beta$-arr2 and CXCR2 in these specimens showed $\beta$-arr2 was losing during lung cancer metastasis to lymph nodes, in both ADC and SCC specimens (Figure 2). Notably, when cells were in blood or lymph vessels, $\beta$-arr2 was almost absolutely depleted. Conversely, CXCR2 expression was higher in vessels and MLN than in primary lesions. To confirm this presentation, we used the Wilcoxon signed-rank test to analyze $\beta$-arr2 and CXCR2 expression between paired primary tumors and MLNs. $\beta$-arr2 expression was significantly lower in MLNs than primary lesions $(Z=-2.315 ; P=0.021)$, whereas CXCR2 was expressed significantly more in MLNs than in primary lesions $(Z=-3.712 ; P<0.001$; Table $2 b$ ).

\section{A. $\beta$-arr2}

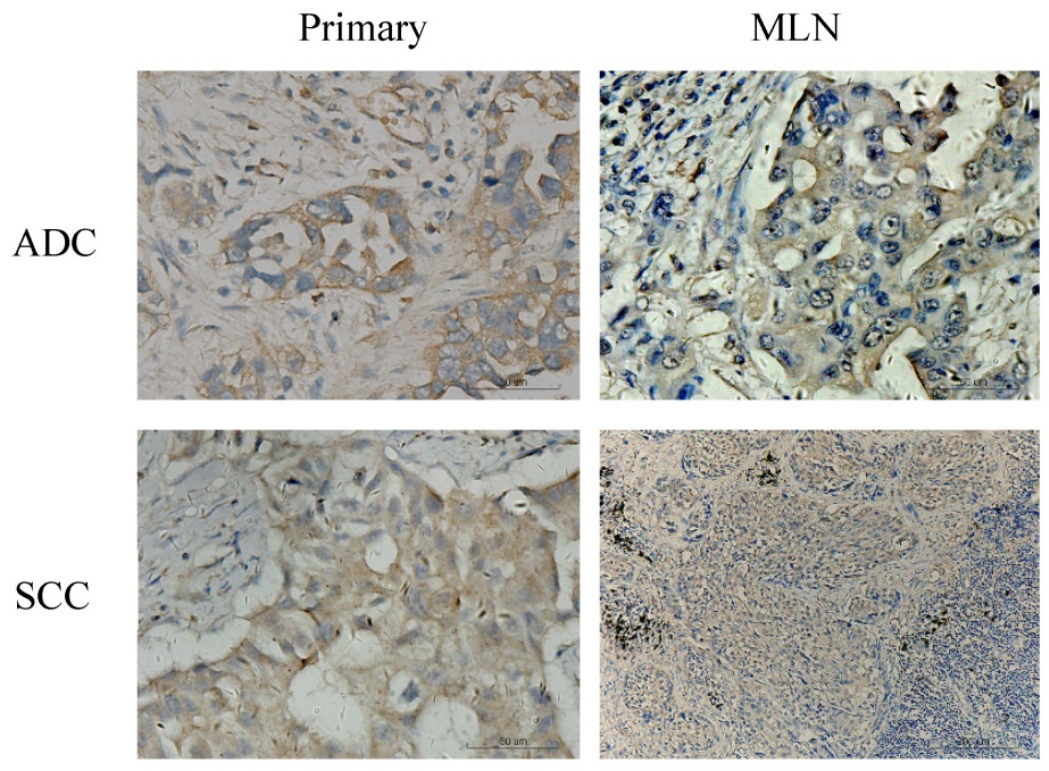

\section{B. $\mathrm{CXCR} 2$}

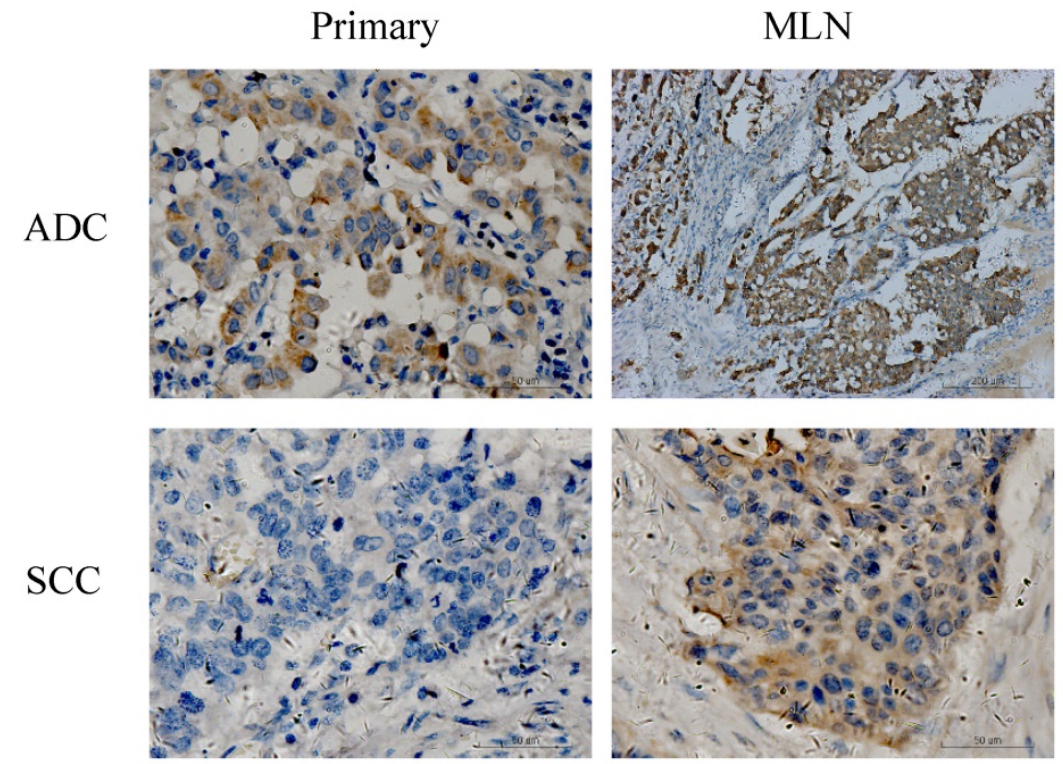

Figure 2. Expression of $\beta$-arr2 and CXCR2 differ in primary NSCLC tumors and metastatic lymph nodes (MLN). A. Different expression of $\beta$-arr2 in primary tumors and MLN. B. Different expression of CXCR2 in primary tumors and MLN. 
Table 2 b. $\beta$-arrestin- 2 and CXCR 2 expressions in paired primary tumors and metastatic Lymph nodes

\begin{tabular}{|c|c|c|c|c|c|c|c|c|c|c|c|c|}
\hline \multirow{3}{*}{$\begin{array}{l}\text { Lesion's } \\
\text { Position }\end{array}$} & \multicolumn{6}{|c|}{$\beta$-arrestin-2 } & \multicolumn{6}{|c|}{ CXCR2 } \\
\hline & \multicolumn{6}{|c|}{ No. of patients } & \multicolumn{6}{|c|}{ No. of patients } \\
\hline & 0 & 1 & 2 & 3 & $Z^{*}$ & $\begin{array}{l}P \\
\text { value }\end{array}$ & 0 & 1 & 2 & 3 & $Z^{*}$ & $P$ value \\
\hline Primary & 21 & 15 & 33 & 18 & -2.315 & 0.021 & 33 & 29 & 23 & 2 & -3.712 & $<0.001$ \\
\hline Metastasis & 14 & 42 & 31 & 0 & & & 11 & 37 & 31 & 8 & & \\
\hline
\end{tabular}
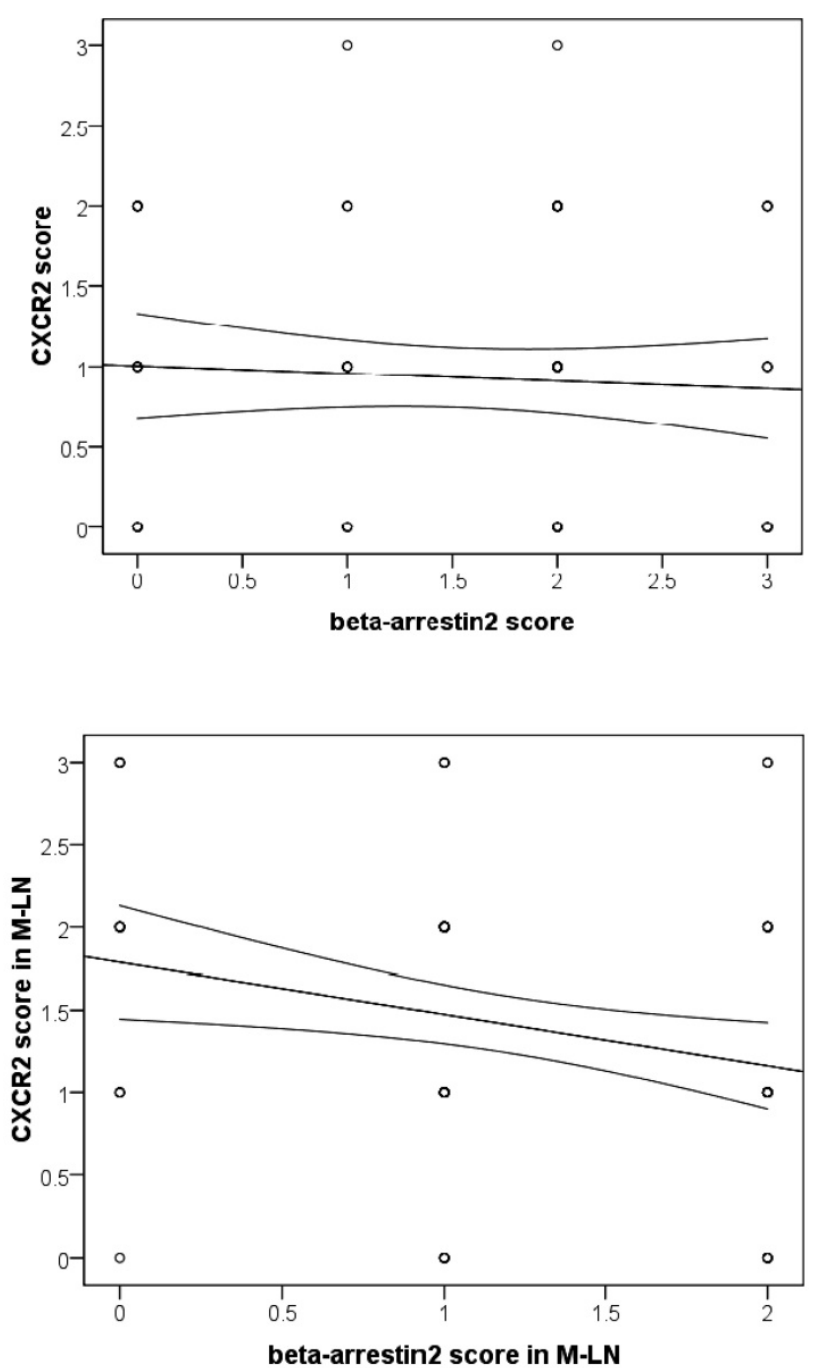

Figure 3. Analysis of $\beta$-arr2 and CXCR2 expressions in primary NSCLC tumors and MLNs (Spearman rank coefficient). No relationship was seen for primary tumors, however, an inverse relationship was seen in MLNs $(r=-0.263$, $P=0.012$ ).

\section{$\beta$-arr2 associated with CXCR2 in MLN}

As we observed, $\beta$-arr2 expression decreased, whereas CXCR2 increased, in the process of lymph node metastasis. As combining with $\beta$-arr2 is a mediator of GPCR desensitization and endocytosis, we inferred that $\beta$-arr2 modulates lymph node metastasis by activating CXCR2. Therefore, we analyze the relationships between $\beta$-arr2 and CXCR2. Although no relationship between $\beta$-arr2 and CXCR2 was observed in primary lesions $(\mathrm{r}=-0.065, P=0.548)$, an inverse relationship was observed in MLNs $(\mathrm{r}=-0.263, \quad P=0.012$; Spearman rank correlation coefficient; Figure 3).

\section{$\beta$-arr2 ${ }^{\text {Low }} \&$ CXCR2 ${ }^{\text {High }}$ in MLN correlated with poor prognosis of NSCLC}

$\beta$-arr2 levels decrease during NSCLC metastasis to lymph nodes, for both ADC and SCC tumors (Figure 2), whereas CXCR2 expression was higher in MLNs than in primary lesions. As we had found expressions of $\beta$-arr2 and CXCR2 in MLNs to be inversely related, we sorted 36 patients with $\beta$-arr2 high \& CXCR2 low expressions in MLN ( $\beta$-arr2 $2^{\text {High} / C X C R 2 ~}{ }^{\text {Low }}$ group) and 38 patients with $\beta$-arr2 low \& CXCR2 high expressions in $\operatorname{MLN}\left(\beta\right.$-arr2 ${ }^{\text {Low }} / C X C R 2^{\text {High }}$ group), and used a Kaplan-Meier survival curve to compare their OS. We found the $\beta$-arr2 $2^{\text {Low }} /$ CXCR2 ${ }^{\text {High }}$ group had worse 4-year OS (Log-rank: $\chi^{2}=5.926, P=0.015$; Figure 4).

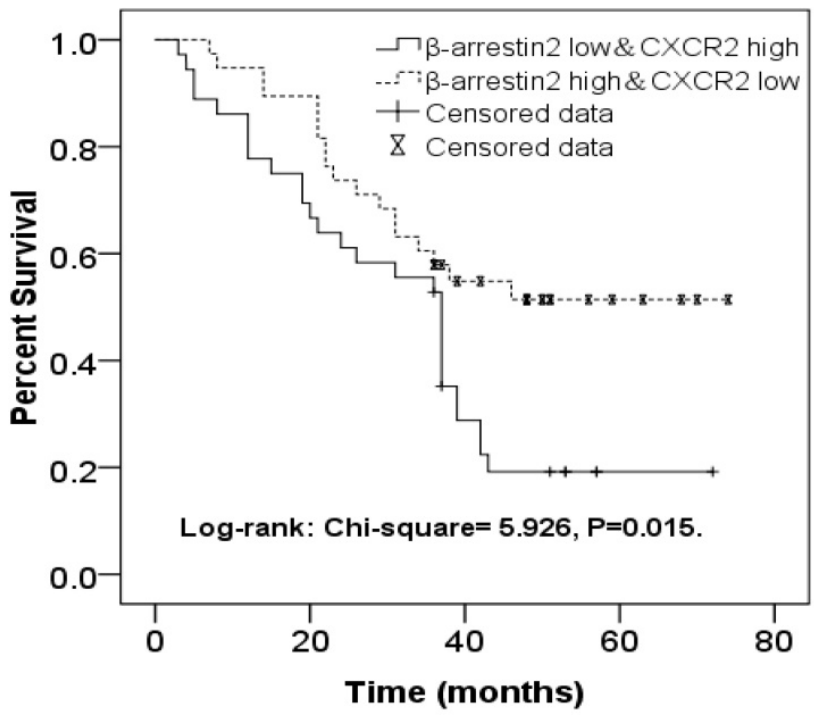

Figure 4. Kaplan-Meier survival curve comparing NSCLC patients with $\beta$-arr2High/CXCR2Low expression $(n=36)$ and those with $\beta$-arr2Low/CXCR2High expression $(n=38)$ in metastatic lymph nodes. The $\beta$-arr2Low/CXCR2High group had significantly worse 4-year overall survival (Log-rank: $X^{2}=5.926, P=0.015$ ).

\section{Discussion}

Lymph node metastasis affects therapy options, prognosis and survival of NSCLC [11-13]. Cancer cells usually accumulate critical genetic changes during metastasis, including activation of metastasis-related genes and inactivation or deletion of suppressor genes [14-16]. Increasing evidence indicates that cancer-related inflammation plays important roles in tumorigenesis and metastasis [17-18]. The CXC chemokines have indispensable functions in 
cancer-related inflammation. The $\mathrm{ELR}^{+}$chemokines, which induce cellular response via CXCR2, are reportedly associated with malignant transformation, cell migration, angiogenesis, tumorigenesis, and metastasis of lung cancer [1, 2].

In the present study, we confirmed that $\beta$-arr2 modulated lymph node metastasis from NSCLC through activation of CXCR2. First, we analyzed the relationships between $\beta$-arr2/CXCR2 expression and lymph node metastasis, and found that both lower $\beta$-arr2 and higher CXCR2 expression were associated with lymph node metastasis. Second, we compared expression of $\beta$-arr2 and CXCR2 between paired primary tumor and MLN sets and found that $\beta$-arr2 expression is significantly lower at MLNs than at primary lesions, whereas CXCR2 expression is significantly higher in MLNs than in primary lesions. Third, we analyzed the relationships between $\beta$-arr2 and CXCR2 in primary lesions and MLNs, and found no relationship between their expressions in primary lesions, but a significantly inverse relationship in MLNs. Taken together and with previous studies, this data indicates that $\beta$-arr2 modulates NSCLC lymph node metastasis through activating CXCR2. To further confirm, we followed up all the patients for at least 48 months, and found that patients with $\beta$-arr2 $2^{\text {Low }} /$ CXCR2 $2^{\text {High }}$ expression in MLNs had a poorer prognosis. This result suggests that $\beta$-arr2 loss and CXCR2 activation are associated with both NSCLC lymph node metastasis and unfavorable prognosis for patients with NSCLC.

$\beta$-arrestins are not only mediators for GPCR, but also scaffold in many intracellular signaling networks such as the Hedgehog, Wnt, Notch, and TGFb pathways; they also interact with downstream kinases including the MAPK and Akt cascades [7, 8, 19-21]. Involvement of arrestins in so many independent signaling events indicates their indispensability for these multifaceted molecular processes [22, 23]. Recent studies have shown that $\beta$-arr2 mediates T $\beta$ RIII-induced inhibition of NFKB-dependent cell migration [24]; and it may also serve as an E3 ligase adaptor for TRAF6 toward TAK1 [25]. These studies and our present findings indicate that $\beta$-arr2 has an important function in cancer cell growth and migration.

Higher expression levels of CXCR2 ligands were observed in several tumor types, including melanoma, lung and colon carcinoma cells, and was associated with tumor angiogenesis and leukocyte infiltration [26-28]. CXCR2-deficient mice displayed impaired angiogenesis and tumor development [29, 30]. These studies suggest that CXCR2 is crucial to tumor development, which is also supported by our data. Our data imply that higher CXCR2 expression is associated with lymph node metastasis and poor prognosis. We also found CXCR2 expression was significantly higher in MLN than in primary lesions (Wilcoxon signed-rank test); and that $\beta$-arr2 and CXCR2 were significantly inversely expressed in MLNs. Previous studies suggest that $\beta$-arr2 modulates tumorigenesis by regulating inflammation and angiogenesis through activation of CXCR2 in vitro $[2,6,8,9]$. Together, these data suggest that $\beta$-arr2 regulates lymph node metastasis of lung carcinoma by up-regulation of CXCR2.

\section{Acknowledgements}

This work was supported by the Key Research and Development Program of Shandong Province (2015GSF118129), National Natural Science Foundation of China (project 81301728) and Shandong Provincial Natural Science Foundation, China (ZR2015HQ020). The funders had no role in study design, data collection and analysis, decision to publish, or preparation of the manuscript.

\section{Competing Interests}

The authors have declared that no competing interest exists.

\section{References}

1. Ok S, Kim SM, Kim C, Nam D, Shim BS, Kim SH, et al. Emodin inhibits invasion and migration of prostate and lung cancer cells by downregulating the expression of chemokine receptor CXCR4. Immunopharmacol Immunotoxicol. 2012; 34: 768-78.

2. Raghuwanshi SK, Nasser MW, Chen X, Strieter RM, Richardson RM. Depletion of beta-arrestin-2 promotes tumor growth and angiogenesis in a murine model of lung cancer. J Immunol. 2008; 180: 5699-706.

3. Addison CL, Daniel TO, Burdick MD, Liu H, Ehlert JE, Xue YY, et al. The CXC chemokine receptor 2, CXCR2, is the putative receptor for ELR+ CXC chemokine-induced angiogenic activity. J Immunol. 2000; 165: 5269-77.

4. Heidemann J, Ogawa H, Dwinell MB, Rafiee P, Maaser C, Gockel HR, et al. Angiogenic effects of interleukin 8 (CXCL8) in human intestinal microvascular endothelial cells are mediated by CXCR2. J Biol Chem. 2003; 278: 8508-15.

5. Fan GH, Yang W, Wang XJ, Qian Q, Richmond A. Identification of a motif in the carboxyl terminus of CXCR2 that is involved in adaptin 2 binding and receptor internalization. Biochemistry. 2001; 40: 791-800.

6. Richardson RM, Marjoram RJ, Barak LS, Snyderman R. Role of the cytoplasmic tails of CXCR1 and CXCR2 in mediating leukocyte migration, activation, and regulation. J Immunol. 2003; 170: 2904-11.

7. Zhao M, Wimmer A, Trieu K, Discipio RG, Schraufstatter IU. Arrestin regulates MAPK activation and prevents NADPH oxidase-dependent death of cells expressing CXCR2. J Biol Chem. 2004; 279: 49259-67.

8. Barlic J, Andrews JD, Kelvin AA, Bosinger SE, DeVries ME, Xu L, et al. Regulation of tyrosine kinase activation and granule release through beta-arrestin by CXCRI. Nat Immunol. 2000; 1: 227-33.

9. Su Y, Raghuwanshi SK, Yu Y, Nanney LB, Richardson RM, Richmond A. Altered CXCR2 signaling in beta-arrestin-2-deficient mouse models. J Immunol. 2005; 175: 5396-402.

10. Bachmann IM, Puntervoll HE, Otte AP, Akslen LA. Loss of BMI-1 expression is associated with clinical progress of malignant melanoma. Mod Pathol. 2008; 21: 583-90.

11. Rusch VW, Hawes D, Decker PA, Martin SE, Abati A, Landreneau RJ, et al. Occult metastases in lymph nodes predict survival in resectable non-small-cell lung cancer: report of the ACOSOG Z0040 trial. J Clin Oncol. 2011; 29: 4313-9.

12. Wang CL, Li Y, Yue DS, Zhang LM, Zhang ZF, Sun BS. Value of the metastatic lymph node ratio for predicting the prognosis of non-small-cell lung cancer patients. World J Surg. 2012; 36: 455-62.

13. Saji H, Tsuboi M, Yoshida K, Kato Y, Nomura M, Matsubayashi J, et al. Prognostic impact of number of resected and involved lymph nodes at complete resection on survival in non-small cell lung cancer. J Thorac Oncol. 2011; 6: 1865-71.

14. Kuonen F, Laurent J, Secondini C, Lorusso G, Stehle JC, Rausch T, et al. Inhibition of the Kit ligand/c-Kit axis attenuates metastasis in a mouse model 
mimicking local breast cancer relapse after radiotherapy. Clin Cancer Res. 2012; 18: 4365-74.

15. Fazi F, Fontemaggi G. MicroRNAs and lymph node metastatic disease in lung cancer. Thorac Surg Clin. 2012; 22: 167-75.

16. Sun L, Zhang Q, Luan H, Zhan Z, Wang C, Sun B. Comparison of KRAS and EGFR gene status between primary non-small cell lung cancer and local lymph node metastases: implications for clinical practice. J Exp Clin Cancer Res. 2011; 30: 30

17. Boulard O, Kirchberger S, Royston DJ, Maloy KJ, Powrie FM. Identification of a genetic locus controlling bacteria-driven colitis and associated cancer through effects on innate inflammation. J Exp Med. 2012; 209: 1309-24.

18. Kreiseder B, Orel L, Bujnow C, Buschek S, Pflueger M, Schuett W, et al. Alpha-catulin down-regulates E-cadherin and promotes melanoma progression and invasion. Int J Cancer. 2013; 132: 521-30.

19. Sun Y, Cheng Z, Ma L, Pei G. Beta-arrestin2 is critically involved in CXCR4-mediated chemotaxis, and this is mediated by its enhancement of $\mathrm{p} 38$ MAPK activation. J Biol Chem. 2002; 277: 49212-9.

20. Tohgo A, Pierce KL, Choy EW, Lefkowitz RJ, Luttrell LM. beta-Arrestin scaffolding of the ERK cascade enhances cytosolic ERK activity but inhibits ERK-mediated transcription following angiotensin AT1a receptor stimulation. Jiol Chem. 2002; 277: 9429-36.

21. Tohgo A, Choy EW, Gesty-Palmer D, Pierce KL, Laporte S, Oakley RH, et al. The stability of the $\mathrm{G}$ protein-coupled receptor-beta-arrestin interaction determines the mechanism and functional consequence of ERK activation. J Biol Chem. 2003; 278: 6258-67.

22. Kovacs JJ, Hara MR, Davenport CL, Kim J, Lefkowitz RJ. Arrestin development: emerging roles for beta-arrestins in developmental signaling pathways. Dev Cell. 2009; 17: 443-58.

23. Buchanan FG, DuBois RN. Emerging roles of beta-arrestins. Cell Cycle. 2006; 5: 2060-3.

24. You HI, How T, Blobe GC. The type III transforming growth factor-beta receptor negatively regulates nuclear factor kappa B signaling through its interaction with beta-arrestin2. Carcinogenesis. 2009; 30: 1281-7.

25. Wang Y, Tang Y, Teng L, Wu Y, Zhao X, Pei G. Association of beta-arrestin and TRAF6 negatively regulates Toll-like receptor-interleukin 1 receptor signaling. Nat Immunol. 2006; 7: 139-47.

26. Varney ML, Johansson SL, Singh RK. Distinct expression of CXCL8 and its receptors CXCR1 and CXCR2 and their association with vessel density and aggressiveness in malignant melanoma. Am J Clin Pathol. 2006; 125: 209-16.

27. Zhu YM, Webster SJ, Flower D, Woll PJ. Interleukin-8/CXCL8 is a growth factor for human lung cancer cells. Br J Cancer. 2004; 91: 1970-6.

28. Wislez M, Fujimoto N, Izzo JG, Hanna AE, Cody DD, Langley RR, et al. High expression of ligands for chemokine receptor CXCR2 in alveolar epithelial neoplasia induced by oncogenic kras. Cancer Res. 2006; 66: 4198-207.

29. Keane MP, Belperio JA, Xue YY, Burdick MD, Strieter RM. Depletion of CXCR2 inhibits tumor growth and angiogenesis in a murine model of lung cancer. J Immunol. 2004; 172: 2853-60.

30. Mestas J, Burdick MD, Reckamp K, Pantuck A, Figlin RA, Strieter RM. The role of CXCR2/CXCR2 ligand biological axis in renal cell carcinoma. J Immunol. 2005; 175: 5351-7. 